\title{
Interval between insulin injection and breakfast in diabetes
}

\author{
A H Sackey, I G Jefferson
}

\begin{abstract}
The relationship between the insulinbreakfast interval, postprandial increase in blood glucose, and glycaemic control was studied in $\mathbf{5 8}$ children with diabetes. Patients recorded insulin-breakfast intervals in a home diary over a seven day period, and during a 24 hour period at the weekend provided eight serial capillary dried blood spots for glucose analysis.

The highest mean blood glucose value occurred two hours after breakfast and showed a significant correlation with fructosamine concentrations. Weekend insulin-breakfast intervals ranged from 2-30 minutes, with 70\% reporting intervals of less than 15 minutes. There was a significant correlation between the weekend insulin-breakfast interval and the after breakfast increase in blood glucose with a mean increment of $0.4 \mathrm{mmol} / \mathrm{l}$ in the 30 minute group and $7 \cdot 2 \mathrm{mmol} / \mathrm{l}$ in the 2 minute group. Over the whole study period, children with mean insulin-breakfast intervals of two to 12 minutes had a mean fructosamine concentration of 376 $\mu \mathrm{mol} / \mathrm{l}$ compared with $341 \mu \mathrm{mol} / \mathrm{l}$ in those with intervals of 15-35 minutes.

This study has shown that the interval between insulin injection and breakfast significantly influences the morning postprandial rise in blood glucose and consequently short term glycaemic control. It is therefore important that patients are encouraged to leave an interval of about 30 minutes between insulin injection and breakfast.

(Arch Dis Child 1994; 71: 248-250)
\end{abstract}

Relatively little has been published on the effect of the interval between insulin injection and breakfast on increment in postprandial glucose. ${ }^{12}$ Previous studies have examined this association under controlled conditions in a small number of patients. ${ }^{12}$ This study was carried out to determine the intervals used by patients in a children's diabetes clinic and to ascertain any relationships, under ordinary living conditions, between their insulin-breakfast interval, postprandial increase in blood glucose, and short term glycaemic control as measured by fructosamine and longer term control by glycated haemoglobin $\left(\mathrm{HbAl}_{\mathrm{c}}\right)$.

\section{Patients and methods}

METHODS

Patients were recruited from among the 135 children who attend the Hull and East
Yorkshire children's diabetes clinic. Over a three month period all children who had had diabetes for more than one year and were due for a routine clinic (total of 64 patients) were sent an information sheet one week before that visit. They were provided with a diary in which to record daily activity, insulin injection, and meal times. During the weekend preceding the clinic visit each child performed, at home, eight capillary blood glucose tests during a 24 hour period: before and two hours after each main meal (BG1 to BG6 respectively), at bedtime (BG7), and at 3 am (BG8). At each of these times a blood spot was blotted onto a preprinted filter paper (Schleicher and Schull, Germany) and brought along to the clinic. The dried blood spots were eluted using perchloric acid and the eluate analysed for glucose concentration (Merck Granutest 100 kit).

The diaries were reviewed with particular attention to injection and meal times. Patients who failed to provide a detailed diary were asked specifically about injection-meal intervals during the week and at weekends. The insulin-breakfast intervals often varied from day to day and therefore separate values were determined for the weekend, weekdays, and for the whole study period. Weekend insulin-breakfast intervals were correlated with the blood glucose series (which were performed during that weekend). The variation in mean insulin-breakfast intervals for the whole study period was compared with fructosamine concentrations obtained at the end of that period. Venous blood samples were obtained for estimation of $\mathrm{HbAl}_{c}$ (Ciba Corning 765 Glycomat) and fructosamine (Roche kit, Unimate 5 ). $\mathrm{HbA} 1_{c}$ is reported as the ratio of the predominant fraction $\mathrm{HbA} 1_{c}$ to the total $\mathrm{HbA}$.

Comparisons were analysed by unpaired $t$ test and correlations performed by simple linear regression analysis.

\section{PATIENTS}

Sixty four patients were recruited and 58 provided satisfactory dried blood spots for analysis. Their age range was $4 \cdot 1$ to $18 \cdot 5$ years with a mean (SD) of $12.3(3.5)$ years. There were 32 females, age range $5 \cdot 8$ to $18 \cdot 1$ years, mean (SD) of $12.2(3.2)$; and 26 males, age range 4.1 to 18.5 years, mean (SD) of 12.5 $(4 \cdot 0)$. Fifty six patients were receiving twice daily injections of mixed component human insulin and two patients were on once daily long acting insulin (Ultratard, Novo Nordisk) and preprandial short acting insulin. Insulin doses ranged from 0.3 to 1.5 units $/ \mathrm{kg}$ with a mean (SD) of $0.9(0.3)$ units $/ \mathrm{kg}$. 


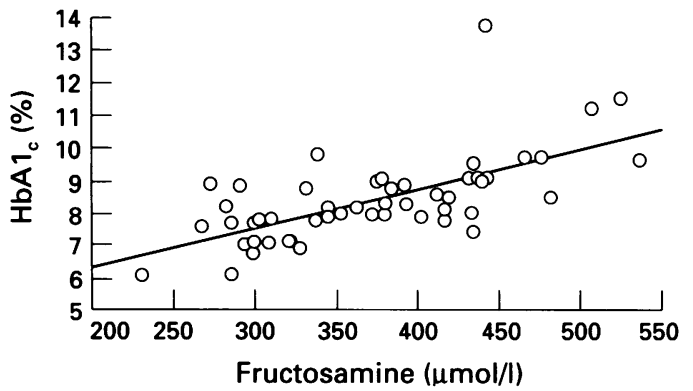

Figure 1 Relationship between fructosamine and $H b A 1_{\mathrm{c}}$.

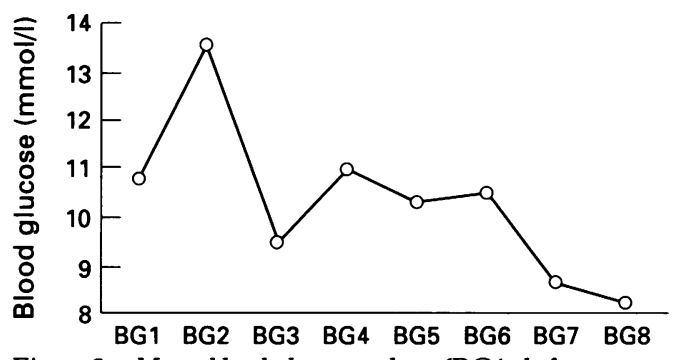

Figure 2 Mean blood glucose values ( $B G 1$ : before breakfast, BG2: two hours after breakfast, BG3: before lunch, BG4: two hours after lunch, BG5: before supper, BG6: two hours after supper, BG7: before bed, and BG8: 3 am).

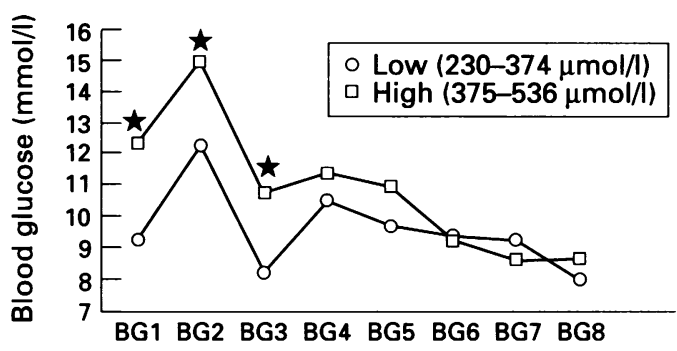

Figure 3 Comparison of mean blood glucose values in children with high and low fructosamine concentrations; ${ }^{\star} B G 1, p=0.02 ; B G 2, p=0.04 ; B G 3, p=0.03$;

$B G 4-B G 8$ were not significant. (BG1: before breakfast, BG2: two hours after breakfast, BG3: before lunch, BG4: two hours after lunch, BG5: before supper, BG6: two hours after supper, BG7: before bed, BG8: 3 am.)

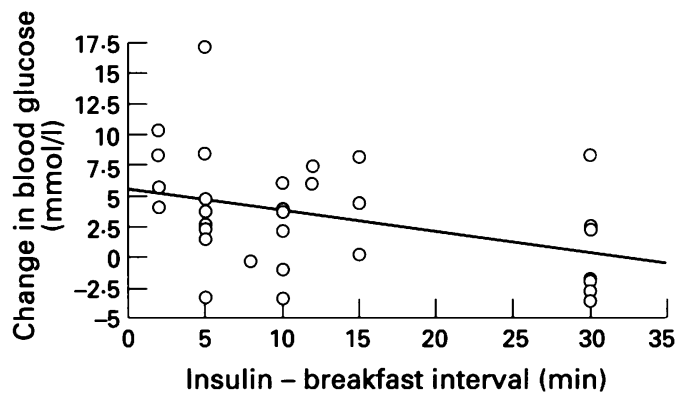

Figure 4 Relationship between insulin-breakfast interval and morning postprandial increase in blood glucose.

Table 1 Blood glucose values

\begin{tabular}{lllllllll}
\hline & $B G 1$ & $B G 2$ & $B G 3$ & $B G 4$ & $B G 5$ & $B G 6$ & $B G 7$ & $B G 8$ \\
\hline No $^{\star}$ & 44 & 43 & 45 & 43 & 44 & 44 & 43 & 37 \\
Mean & $10 \cdot 8$ & $13 \cdot 6$ & $9 \cdot 5$ & 11 & $10 \cdot 3$ & $9 \cdot 5$ & $8 \cdot 6$ & $8 \cdot 2$ \\
SD & $5 \cdot 2$ & $4 \cdot 9$ & $4 \cdot 5$ & $4 \cdot 9$ & $5 \cdot 4$ & $5 \cdot 4$ & $5 \cdot 1$ & $4 \cdot 2$ \\
Range & $2 \cdot 4-24$ & $4 \cdot 3-22$ & $2 \cdot 2-19$ & $2 \cdot 4-22$ & $2 \cdot 2-24$ & $1 \cdot 2-21$ & $2 \cdot 3-28$ & $2 \cdot 2-16 \cdot 6$
\end{tabular}

BG1: before breakfast, BG2: two hours after breakfast, BG3: before lunch, BG4: two hours after lunch, BG5: before supper, BG6: two hours after supper, BG7: before bed, BG8: 3 am. ^Number of patients from whom dried blood spots were of sufficient size to permit analysis.

\section{Results}

Fructosamine values (normal range 205-285 $\mu \mathrm{mol} / \mathrm{l}$ ) were obtained in 51 patients and ranged from 230 to $536 \mu \mathrm{mol} / 1$ with a mean (SD) of $373(72)$, and median of $374 \mu \mathrm{mol} / /$. $\mathrm{HbAl}_{\mathrm{c}}$ values (normal range $4 \cdot 5-6 \cdot 5 \%$ ) ranged from $6 \cdot 1 \%$ to $13 \cdot 7 \%$ with mean (SD) of $8 \cdot 4(1 \cdot 3)$.

There was a highly significant correlation between fructosamine and $\mathrm{HbAl}_{\mathrm{c}}$ values $\left(\mathrm{p}=0.0001, \quad R=0.65, \quad R^{2}=0.43\right.$; fig 1$)$. Summated blood glucose series results (fig 2 , table 1) showed that the highest rise in blood glucose occurred after breakfast (BG2-BG1). Linear regression analysis showed a significant correlation between fructosamine and $\mathrm{BG} 1$ $(\mathrm{p}=0.002, R=0.5)$, BG2 $(\mathrm{p}=0.05, R=0.3)$, BG3 ( $\mathrm{p}=0.007, R=0.4)$, and BG4 ( $\mathrm{p}=0.048$, $R=0.3$ ); there was also significant correlation between BG4 and $\mathrm{HbAl}_{\mathrm{c}}(\mathrm{p}=0.018, R=0.4)$. When the study patients were divided into two groups based on fructosamine concentrations with group $1<50$ th centile $230-374 \mu \mathrm{mol} / \mathrm{h}$, and group $2>50$ th centile $375-536 \mu \mathrm{mol} /$, the mean blood glucose two hours after breakfast was $12.3 \mathrm{mmol} / 1$ for group 1 compared with $15.0 \mathrm{mmol} / 1$ for group 2 ( $\mathrm{p}=0.04$; fig 3 , table 2 ). Forty five patients provided satisfactory data on weekend insulin-breakfast intervals ranging from 2-30 minutes with a mean of 12 minutes and mode of 5 minutes. Thirty three of these patients had complete data for both BG1 and BG2 thus permitting linear regression analysis (fig 4, table 3) which showed a significant correlation $(p=0.025)$ between the weekend insulinbreakfast interval and after breakfast increase (BG2-BG1) in blood glucose concentration. The mean postprandial increment was 0.4 $\mathrm{mmol} / / \mathrm{l}$ the 30 minute group and $4.2 \mathrm{mmol} / \mathrm{l}$ in the $2-15$ minute group $(p=0.02)$. In the four patients who reported an interval of 2 minutes the mean postprandial increment was $7 \cdot 2$ $\mathrm{mmol} / \mathrm{l}$. There was no significant difference between the ages or insulin doses of children with intervals of 2-15 minutes and those with longer intervals. Over the whole study period, children with mean intervals of 2-12 minutes had a mean fructosamine of $376 \mu \mathrm{mol} / 1$ compared with $341 \mu \mathrm{mol} / 1$ in those with intervals of $15-35$ minutes $(p=0.08)$.

\section{Discussion}

The use of dried blood spot glucose series permits sampling under normal living

Table 2 Comparison of mean blood glucose values in children with high and low fructosamine concentrations

\begin{tabular}{lcllll}
\hline & $\begin{array}{l}\text { Low fructosamine } \\
(230-374\end{array}$ & & \multicolumn{2}{l}{$\begin{array}{l}\text { High fructosamine } \\
(375-536 \mu \text { moll })\end{array}$} \\
\cline { 2 - 3 } \cline { 5 - 6 } \cline { 5 - 6 } & Mean & No of patients & & Mean & No of patients \\
\hline BG1 & $9 \cdot 3$ & 24 & & $12 \cdot 4$ & 18 \\
BG2 & $12 \cdot 3$ & 23 & & $15 \cdot 0$ & 18 \\
BG3 & $8 \cdot 2$ & 23 & & $10 \cdot 7$ & 20 \\
BG4 & $10 \cdot 5$ & 22 & & $11 \cdot 4$ & 19 \\
BG5 & $9 \cdot 7$ & 23 & & $11 \cdot 0$ & 18 \\
BG6 & $9 \cdot 4$ & 23 & & $9 \cdot 2$ & 18 \\
BG7 & $9 \cdot 2$ & 23 & & $8 \cdot 6$ & 17 \\
BG8 & $8 \cdot 0$ & 21 & $8 \cdot 6$ & 14 \\
\hline
\end{tabular}

BG1: before breakfast, BG2: two hours after breakfast, BG3: before lunch, BG4: two hours after lunch, BG5: before supper, BG6: two hours after supper, BG7: before bed, BG8: 3 am. 
Table 3 Insulin-breakfast intervals and associated increments in after breakfast blood glucose

\begin{tabular}{lllr}
\hline $\begin{array}{l}\text { Interval } \\
(\text { min })\end{array}$ & No (\%) & $\begin{array}{l}\text { BG2-BG1† } \\
(\text { mmoll) }\end{array}$ & $\begin{array}{r}\text { BG2-BG1† } \\
\text { mean value }\end{array}$ \\
\hline 2 & $4(10)$ & $4 \cdot 1,5 \cdot 8,8 \cdot 4,10 \cdot 4$ & $7 \cdot 2$ \\
5 & $9(27)$ & $-3 \cdot 3,-0 \cdot 6,1 \cdot 7,2 \cdot 7,2 \cdot 7,3 \cdot 1,3 \cdot 9,4 \cdot 8,8 \cdot 5$ & $2 \cdot 6$ \\
8 & $1(3)$ & $-0 \cdot 6$ & $-0 \cdot 6$ \\
10 & $6(18)$ & $-3 \cdot 4,-1 \cdot 1,2 \cdot 1,3 \cdot 7,3 \cdot 8,6 \cdot 1$ & $1 \cdot 9$ \\
12 & $3(9)$ & $2 \cdot 9,5 \cdot 9,7 \cdot 4$ & $5 \cdot 4$ \\
15 & $3(9)$ & $0 \cdot 2,4 \cdot 3,8 \cdot 1$ & $4 \cdot 2$ \\
30 & $7(21)$ & $-3 \cdot 6,-2 \cdot 9,-2 \cdot 1,-1 \cdot 8,2 \cdot 3,2 \cdot 5,8 \cdot 3$ & $0 \cdot 4$ \\
Total & $33(100)$ & & \\
\hline
\end{tabular}

*Number of patients reporting particular interval.

†BG1: before breakfast; BG2: two hours after breakfast; BG2-BG1: morning postprandial increment in blood glucose. represents the largest increase during the day and is influenced significantly by the interval between insulin injection and breakfast. ${ }^{15}$ Secondly, the blood glucose concentration two hours after breakfast is important in determining short term glycaemic control as shown by the significant correlation with fructosamine. It is also of interest that while there was a significant correlation between the daytime blood glucose and fructosamine, no correlation was found with the blood glucose at bedtime or at $3 \mathrm{am}$. This would suggest that efforts directed at controlling morning blood glucose are likely to be more effective in improving glycaemic control. The highly significant correlation of fructosamine with $\mathrm{HbAl}_{\mathrm{c}}$ suggests that these effects may have important long term implications for the risk of development of microvascular complications. It is therefore clearly important that when patients are seen in diabetic clinics specific inquiry is made about the interval between insulin injection and breakfast, and an attempt made to encourage intervals of about 30 minutes. In this study $70 \%$ of patients used intervals of less than 15 minutes, many from habit and, in a few, due to fear of hypoglycaemia with longer intervals. The risk of hypoglycaemia is known to increase with improvement in glycaemic control and it is possible that patients with low fasting blood glucose may require less insulin when they increase the interval between insulin injection and breakfast. ${ }^{7}$

Another reason for leaving suboptimal intervals, particularly on school days, is insufficient time between getting up and breakfast, though children may lie in bed for a while after waking up. One solution to this problem is to keep insulin at the bedside and give the injection soon after waking up which is often about 30 minutes before breakfast. In this way the early morning period in bed is not unduly interrupted and the longer interval is relatively painlessly achieved. By this simple modification in lifestyle it may be possible to improve glycaemic control. Our patients and their parents appeared keen to adopt this regimen and, like other interventions in diabetes, our role will be to help maintain their motivation.

We are grateful to the parents and children who kindly took part in this study. We wish to acknowledge the help and cooperation of the staff of the children's outpatient department and the biochemistry laboratory at the Hull Royal Infirmary. This study was supported by funds from the parents' group of the Hull and East Yorkshire Children's Diabetes Clinic. blood glucose concentration with which there was no significant correlation $(R=0 \cdot 15$, $\mathrm{p}=0 \cdot 38)$. We found that the 34 children with intervals of up to 15 minutes got out of bed significantly later (8.20 am compared with $7.40 \mathrm{am}, \mathrm{p}=0.03$ ) than those (eight patients) who allowed a 30 minute interval. However, there was no significant correlation between fasting blood glucose and either time of getting up or insulin-breakfast intervals. These findings suggest that, during the weekend, many of our patients only get out of bed when they are ready to eat and therefore tend to leave a shorter interval between insulin and breakfast.

This study confirms that, in general, the morning postprandial rise in blood glucose injection and postprandial metabolic control in diabetic children. BMF 1980; 280: 604-6.

2 Witt MF, White NH, Santiago JV. Roles of site and timing of the morning insulin injection in type 1 diabetes. $\mathcal{F}$ Pediatr 1983; 103: 528-33.

3 Taylor RP, Pennock CA. A comparison of three methods for the estimation of capillary blood glucose in filter paper the estimation of capillary blood glucose in file
spots. Ann Clin Biochem 1982; 19 (Pt 1): 22-5.

spots. Ann Clin Biochem 1982; 19 (Pt 1): 22-5.
4 Scheicher E, Wieland OH. Protein glycation: measurement and clinical relevance. fournal of Clinical Chemistry and and clinical relevance. Foumal of Clince

5 Werther GA, Jenkins PA, Turner PC, Baum JD. Twenty four hour metabolic profiles in diabetic children receiving insulin injections once or twice daily. $B M \mathcal{F}^{\prime} 1980$; 281: 414-8.

6 Heineman $\mathrm{L}$, Heise T, Jorgensen LN, Starke AAR. Action profile of the rapid acting insulin analogue: human insulin B28Asp. Diabet Med 1993; 10: 535-9.

7 Shield JPH, Baum JD. Complications of diabetes in childhood. Diabet Med 1993; 10: 499-502.
1 Kinmonth AL, Baum JB. Timing of pre breakfast insulin 